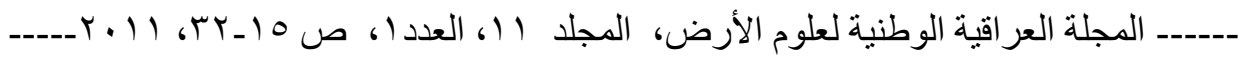

$$
\begin{aligned}
& \text { التحليل السحني وييئة ترسيب تكوين شِرانش في طية بيخير، } \\
& \text { منطقة دهوك، شمال العراق } \\
& \text { رضوان خليل الأتروشي }
\end{aligned}
$$

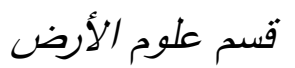

$$
\begin{aligned}
& \text { كلية العلوم } \\
& \text { جامعة كركوك }
\end{aligned}
$$

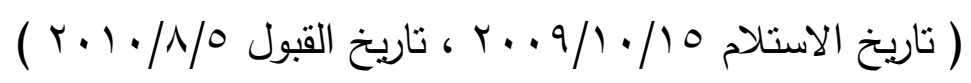

\section{الماخص}

أظهر التحليل السحني الدقيق لتتابعات تكوين شِرانش (بداية الماسترختي المتأخر) في طية بيخير في دي منطقة دهوك، شمالي العراق إنها تتألف من تعاقب سبع سحنات دقيقة، جميعها ذات أرضية ميكراينية وغنية

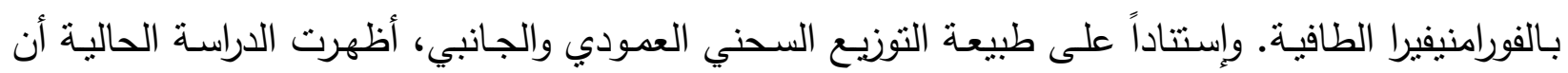
ترسيب هذه التنابعات قد تم ضمن النطاقين البيئيين: الباثيال الأعلى-الأوسط والرصيف الخارجي في خسفة ولئ

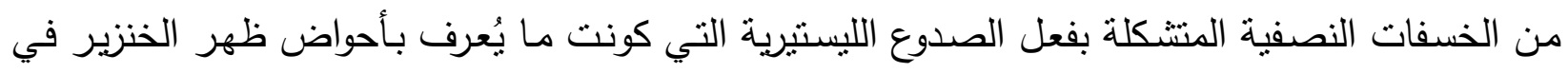

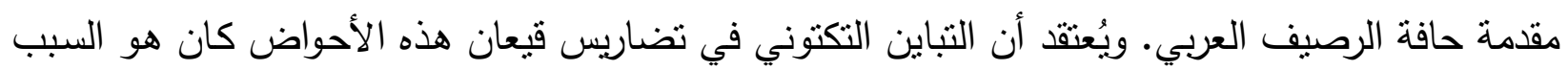

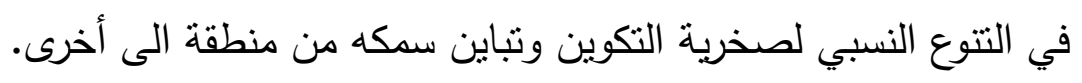

\title{
Facies Analysis and Depositional Environment of Shiranish Formation in Bekhair Anticline, Dohuk Area, Northern Iraq
}

\author{
Abdul Aziz M. Al-Hamdani \\ Department of Geology \\ College of Science \\ Mosul University
}

\author{
Rhadwan K. Al-Atroshi \\ Department of Geology \\ College of Science \\ Kirkuk University
}

\section{ABSTRACT}

The microfacies analysis of the Shiranish Formation (Early-Late Maastrichtian) at the Bekhair anticline, Dohuk area, northern Iraq revealed that the succession is composed of alternation of seven microfacies, which are wholly micritic 


\section{عبدالعزيز محمود الحمداني رضوان خليل الأتروشي}

groundmass and rich in Planktonic Foraminifera. Based on the mode of vertical and lateral distribution, the present study deduced that this succession was deposited at Dohuk area by two environmental zones: upper-middle bathyal and outer shelf within one of the half-graben basin, which formed by Lisstric rifts. The latter was formed by the what so-called "piggy-back" basins at Foreland of the Arabian shelf. It is thought that the lithological and thickness variations at the bases of half-graben basin topography are due to tectonic irregularity.

\section{المقدمة}

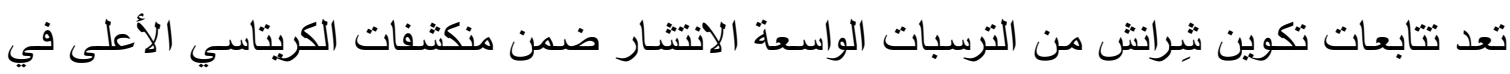

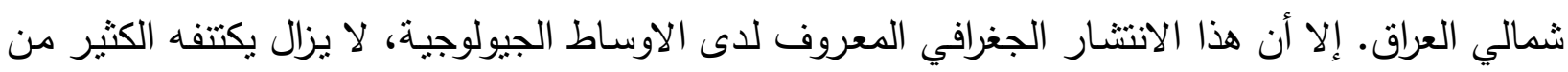

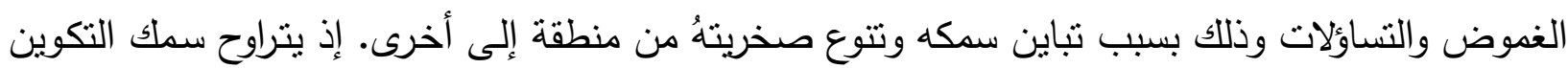

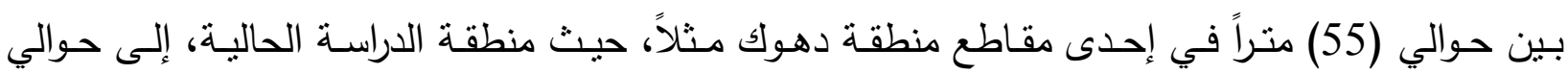
(1500) مترٍ في بئر (ساسان - () الواقعة بجوار مدينة تلعفر (Bellen et al., 1959). أما صخريته فإنها تتتوع من الحجر الجيري والجيري المارلي في تتابعات معظم مكاثفه المعروفة إلى الحجر الجيري

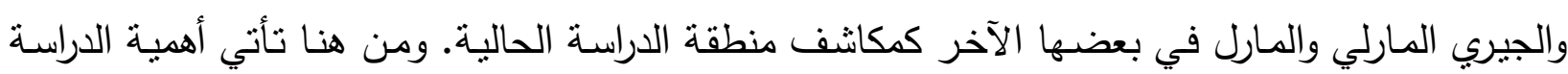

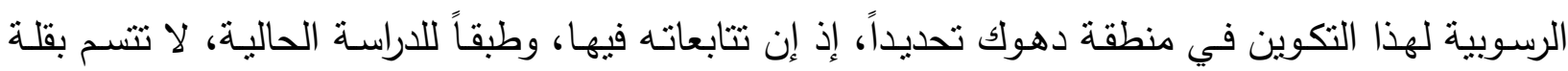

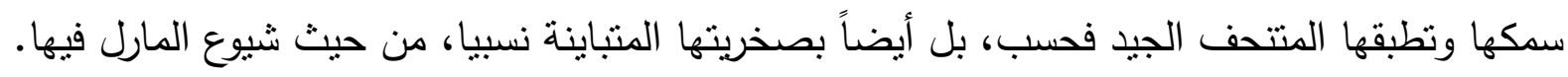
تقع منطقة الدراسة الحالية، المتمثلة بطية بيخير، في شمالي العراق، وعلى امتدادات الأطراف الثمالية

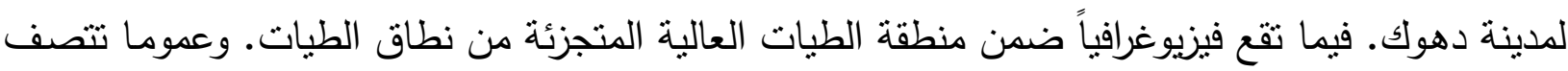

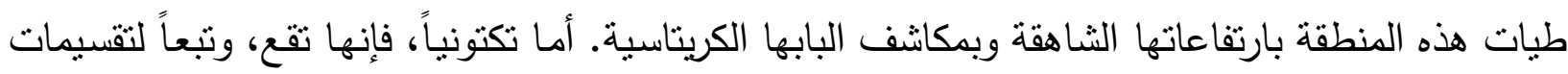

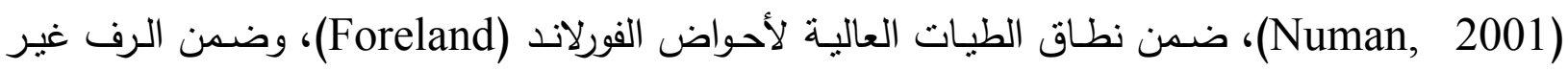

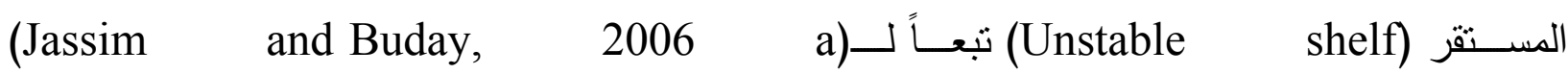

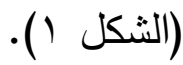

رغم كثرة الدراسـات المتعلقة بتكوين شِرانش في العراق، إلا أن مـا اختص منها بالجوانب الرسوبية

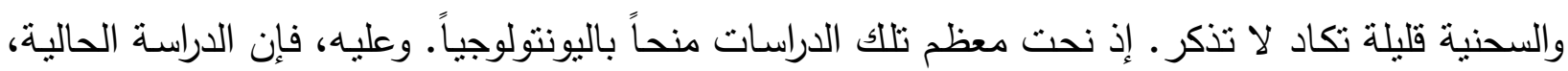
والتي استلت من رسالة الماجستير (Al-atroshi, 2007)، تهدف إلى إظهار نتائج التحليل السحني الدقيق

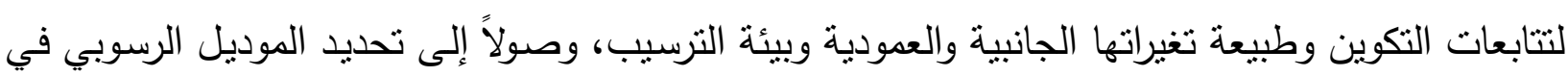
منطقة دهوك، ومن ثم ربطها بالأحداث التكتونية التي حصلت في المنطقة آنذاكت.

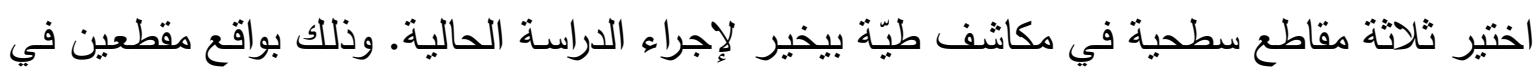

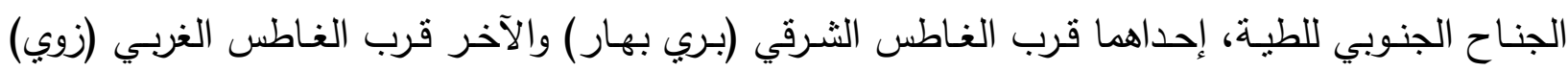
ومقطع واحد في الجناح الثمالي (إيكمالة). وبعد إجراء الوصف الحقلي التفصيلي للنتابعات أُختير (120) 
عينة صخرية من تتابعات المقاطع المختارة وذللك بواقع (41) عينة من مقطع (بري بهار ) و (46) عينة من مقطع (زوي) و (33) عينة من مقطع (إيكمالة) (الثكل r ب).

\section{الطباقية}

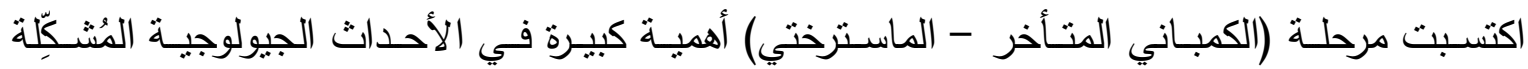
لتضاريس الجغرافية القديمة في العراق والدول المجاورة. فهي اتصفت بالحركة النشطة والفعالة للبلوكات الممتدة

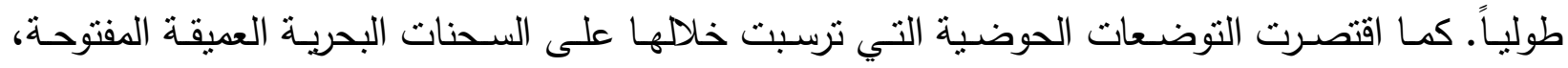

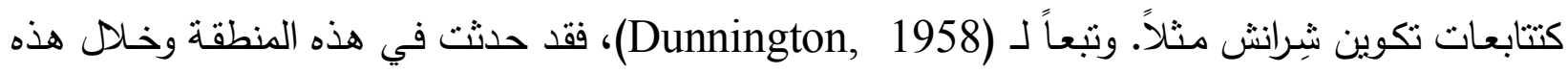
المرحلة الجيولوجية سلسلة من الأحداث تمخضت عنها نراكمات رسوبية تقدمية سميكة ومتتوعة. وتتسم هذها الرواسب الحوضية الكلوبوجيرانية بكثافة تكسراتها وبمحتواها العالي من البتيومين، بل أحياناً بأحتمالية كونها

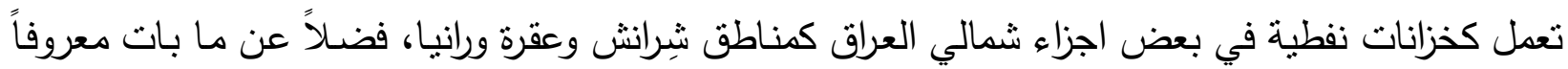

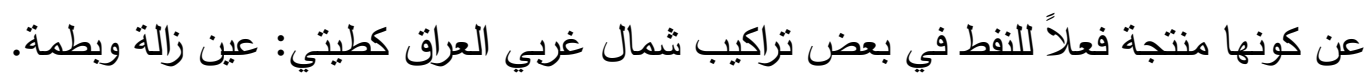

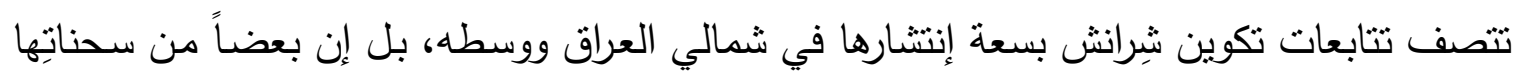

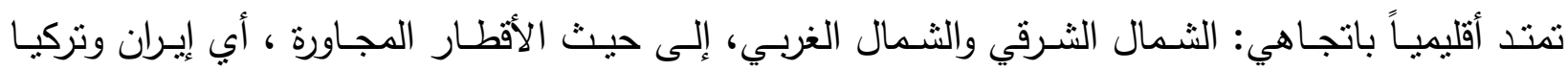

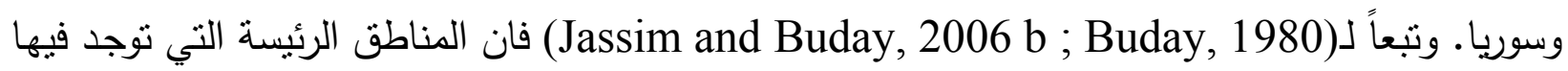

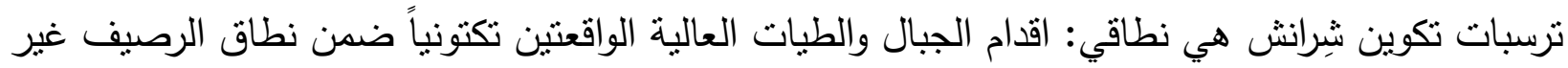

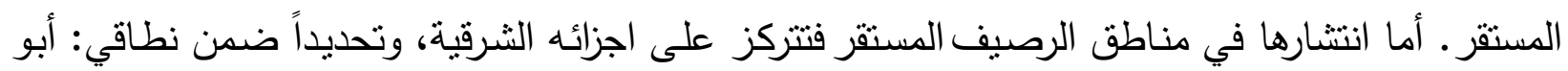

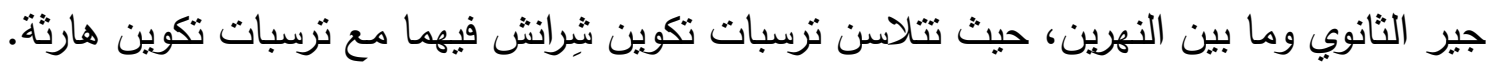

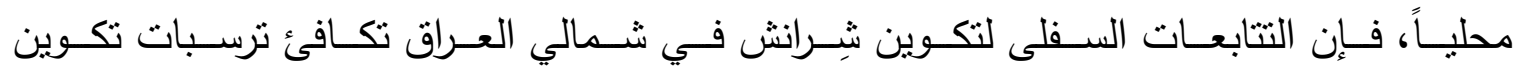

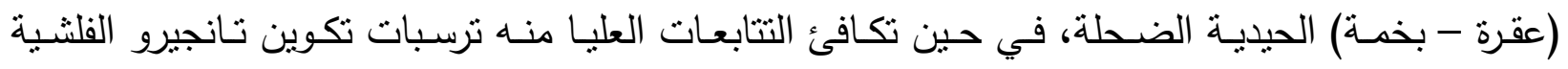
الحوضية العميقة. أما باتجاهي الغرب والجنوب الغربي، حيث نطاق الرصيف المستقر، فإن تتابعات تكويني

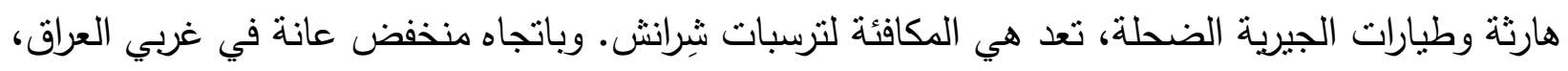

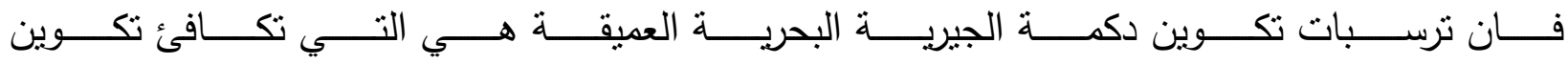

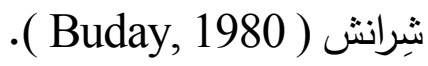

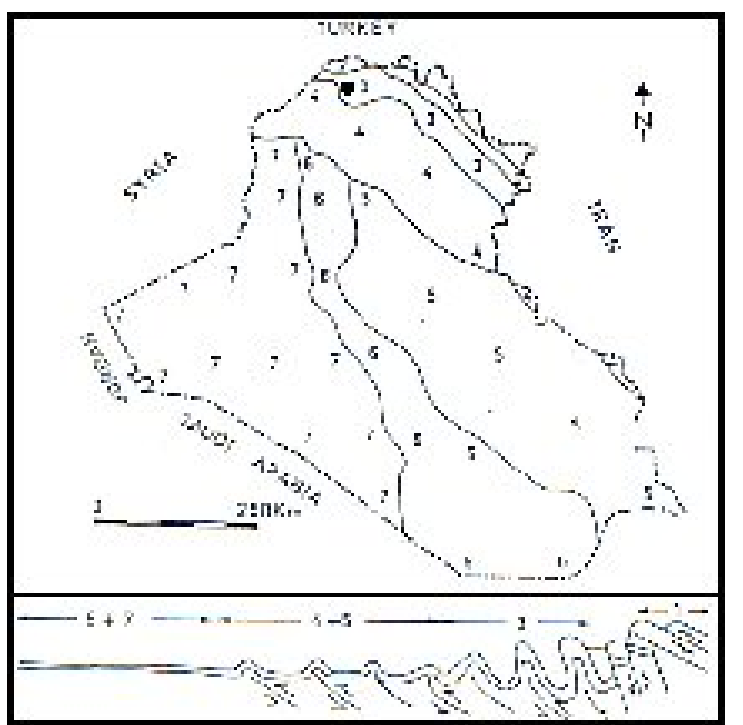


عبدالعزيز محمود الحمداني و رضوان خليل الأتروشي

\begin{tabular}{|c|c|c|}
\hline & Numan, 2001 & Jassim and Buday, 2006 \\
\hline 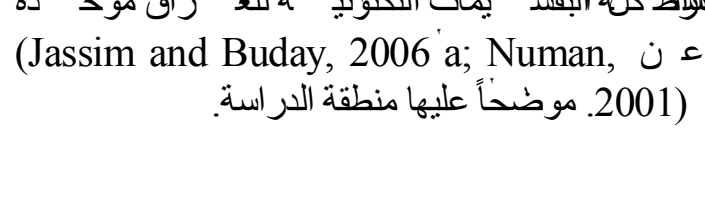 & $\begin{array}{l}\text { 1. Subductional tectonic Facies of } \\
\text { the Zargos Thrust. } \\
\text { 2. Zone of imbrications of the } \\
\text { foreland basin. }\end{array}$ & $\begin{array}{l}\text { 1+2 Zagros Suture Zone } \\
3+4+5 \text { Unstable Shelf } \\
6+7 \text { Stable Shelf }\end{array}$ \\
\hline
\end{tabular}

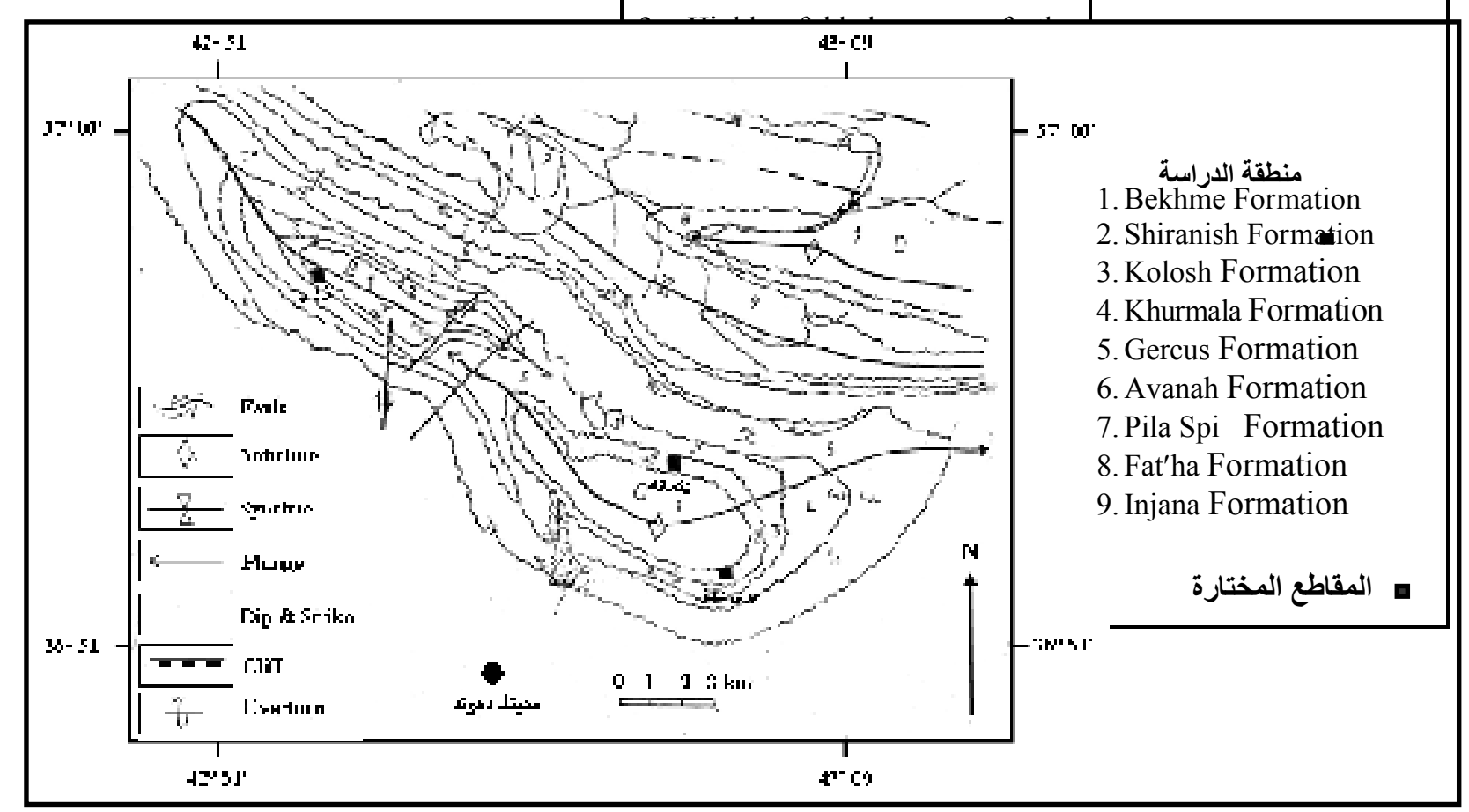

الثكل r: خارطة جيولوجية لطية بيخير (FAO, 1994)، تظهر المقاطع المختارة.

;Bellen et al., ; Henson, 1940 in Bellen et al., 1959 (تنوافق معظم الآراء المطروحة ; ; Al-Qayim, et al., 1986 ; Buday, 1980 ; Kassab, 1973, 1978 ; 1959 Munium, 1976 (Jassim and Buday, 2006 c الطبيعة النوافقية التناسنية المنترجة، حقلياً ومجهرياً، لسطح التماس السفلي لتكوين شِرانش مع تكوين بخمة المكافئ

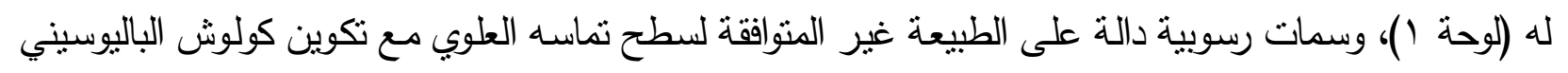
(لوحة r). وتتقسم تتابعات تكوين شِرانش في منطقة دهوك طباقيا على وحدتين، تتألف الوحدة السفلى من تعاقبات

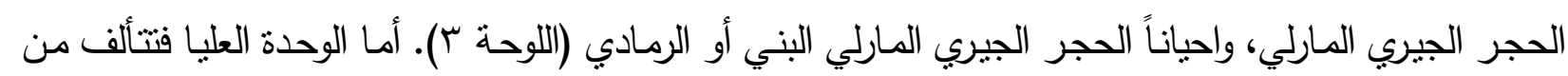

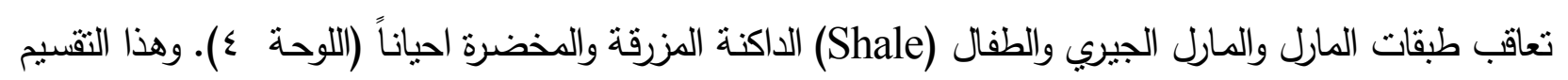
ينوافق مع دراسة كل من (Al- Qayim et al., 1986 و Henson, 1940 in Bellen et al., 1959) وغيرهم.

\section{التحليل السحني}

تنصف ترسبات تكوين شبرانش الجيرية في منطقة الدراسة الحالية، حقلياً بنطبقها المستوي المنتحف الداكن اللون وبنزغرافياً بدعمها الطيني (Mud supported) وبدحتواها العالي من الحبييات الهيكلية (Skeletal grains) المنسمة 
بجودة حفظها وإعتدال نتوعها. ونتكل اصداف الفورامنيفيرا، لا سيما الطافية منها، غالبية الحبييات الهيكلية الموجودة في تتابعات التكوين. فهي تعد بنلك السمة التشخيصية الأولى لهذا التكوين. وعموماً، تتسم اصداف هذه الطافيات بأحجامها اللقيقة وحجيراتها المتعددة ورقة جدرانها وحفظها الجيد. وابرز اجناسـها المشخصـة في ترسبات تكوين شِـرانش هي الـHeterohelix, Globigerinelloides, Globotruncana). اما الفورامنيفيرا القاعية، والتي نأتي بالمرنبة الثانية، فانها تمتاز بتخن جدرانها النسبي وبتضـاغط حجيراتها مقارنة بالفورامنيفيرا الطافية. ومن ابرز اجناسها المشخصة في ترسبات الدراسـة الحاليـة هـي جنسي الـ (Textularia, Nodosaria). كمـا تتضـمن هذه التزسبات القليـل مـن الكالسيسفيرات (Calcispheres) وشوكيات الجلد (Echinodermata) والأوستراكودا والبطنقميات (Gastropoda)، فضلاً عن القليل من حبييات الفتات الصخري الدقيقة (Lithoclastic) الخارجية منها والداخلية. تتألف غالييـة القاعدة الأرضـية أو الحشـوة (Matrix) الموجـودة في ترسبـات تكوين شِرانش مـن الميكرايـت (Micrite)، وبعضها القليل من السبار (Sparite). ويتصف ميكرابت هذا التكوين عموماً بلونه البني الفاتح المنرج أحياناً إلى البني الغامق أو المعتم الباهت وظلك لاحتوائه على المواد العضوية الدقيقة الحجم وتصبغه بالأكاسيد الحيدية، وأحياناً بالمواد البتيومينية. ومن جهة أخرى، يلاحظ أن نسبة ميكرايت هذه التزسبات نتناين من شريحة إلى أخرى. إذ إنها قد تتعدى الا(80\%) من المحتوى الكلي لبعض الثرائح الصخرية، لكنها تتذنى في بعضها الآخر إلى ما يقارب الا(10\%). يتضح من خلال استعراض العمليات التحويرية المشخصة ضمن ترسبات تكوين شِرانش بانها متأثرة، وعلى نطـاق واسـع، بعمليـة الانضـاط (لوحة م). ويعتقد أن السبب في ذلك يعزى الى دقة حبيبات هذه الترسبات ومحتواهـا العـالي من الأطيان الجيريـة، أي الى كونها طينيـة الدعم. أمـا بقيـة العمليات التحويريـة وتأثيراتها في هذه الترسبات مثثل الإذابة والسمنتة والمكرتة والتعكرات الحياتية والنتكل الجديد والإذابـة فإنها عموماً قليلة وثانويـة. وقد تعزى هذه الثحة في جانب منها الى قلة المسامية والنفاذية الأولية في ترسبات

تكوين شِرانش، وبالتالي قلة مسالكها الضرورية لتوغل المحاليل اللازمة لتفعيل العمليات التحويرية فيها.

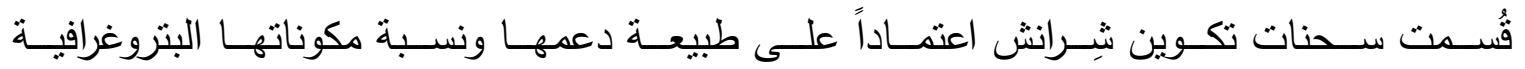
(الأرضـية والحبيـات) وطبيعـة أنسـجتها الأوليـة ومعالمهـا الحقليـة مسن جهـة، ومسـميات نظـام تصـنيف (Dunham, 1962) الجيري المرصسص وسحنة الحجر الجيري الواكي وسحنة الحجر الجيري الطيني. وقُسمت هذه السحنات بدورها، وإعتمـاداً على طبيعة تتوع محتواها الحياتي ووفرته، على سبع سحنات دقيقة ثانويـة، وعلى النحو المبين في أدناه:

ا ـ سحنة الحجر الجيري الطيني الحاوية للقورامنيفيرا الطافية الدقيقة الثانوية (M1) : (Planktonic Foraminiferal lime Mudstone Submicrofacies) :

لا تقل نسبة الميكرايت في هذه السحنة عن (90\%) من محتواها الكلي، حيث انه يؤلف إجمالي القاعدة الأرضية للسحنة. وهو عموماً ذو لون بني متفاوت الثدة وذلك لاختلاطه بالمعادن الطينية والمواد العضوية وصبغات الاكاسيد الحديدية. وتتألف معظم الحبيبات الهيكلية في هذه السحنة، والتي لا تتعدى نسبة وجودها 


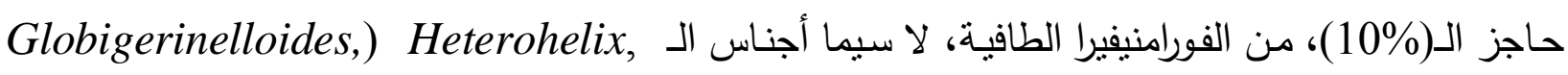
Globotruncana

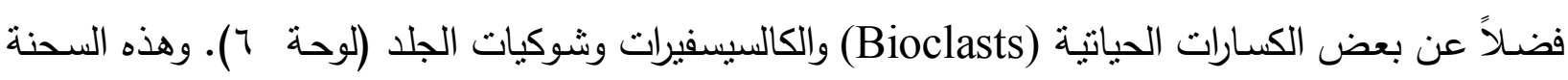

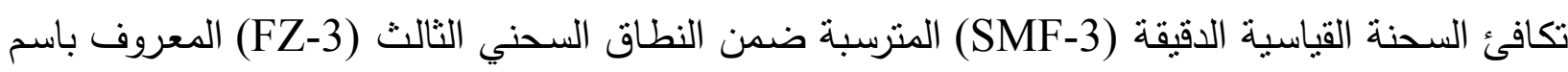

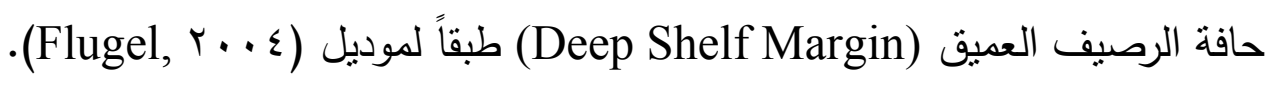

r. سحنة الحجر الجيري الواكي الحاوية للفورامنيفيرا الطافية الدقيقة الثانوية (W1) : (Planktonic Foraminiferal Lime Wackestone Submicrofacies) :

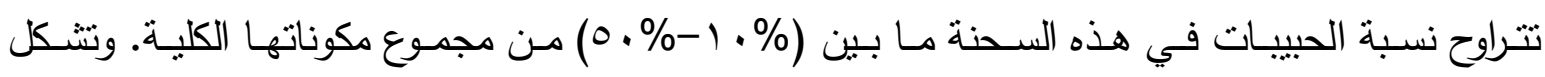

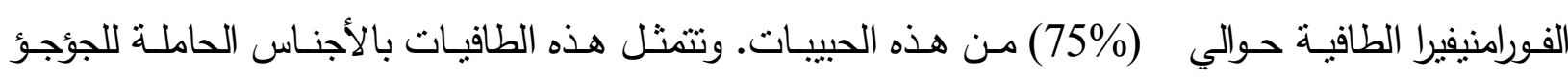

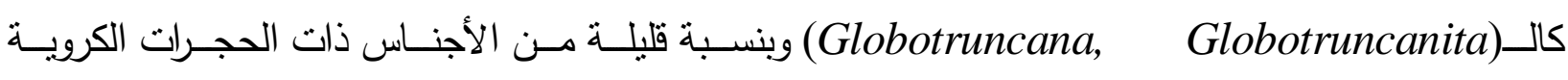

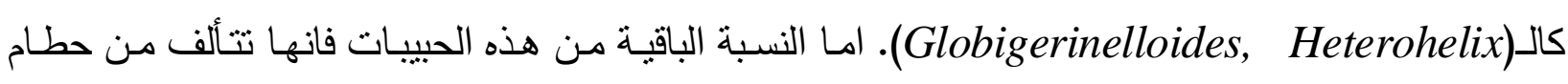

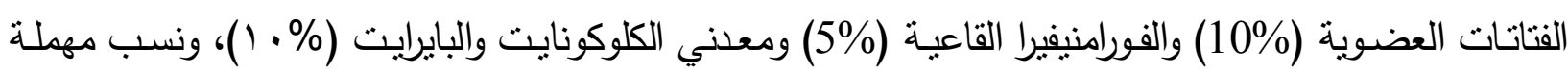

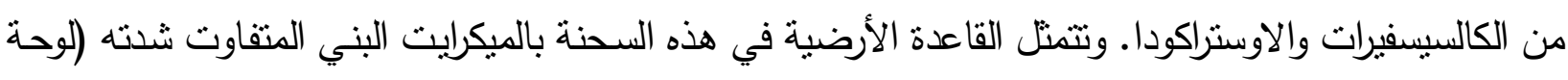

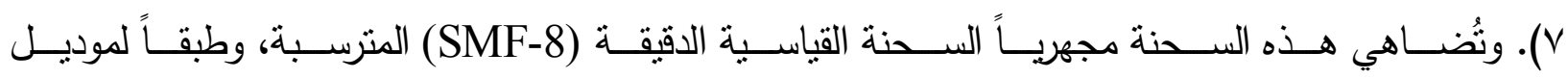

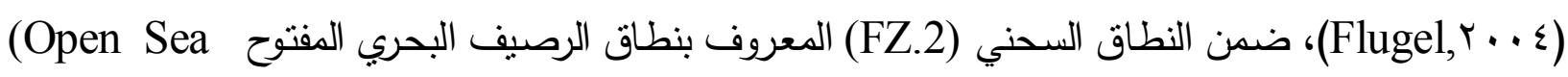
.Shelf)

r. سحنة الحجر الجيري الواكي الحاوية للفتاتات العضوية الدقيقة الثانوية (W2) : (Bioclastic Lime Wackestone Submicrofacies) :

تتكل الفتاتات العضوية في هذه السحنة حوالي (50\%) من مكونات الصخرة، مع وجود لأصداف

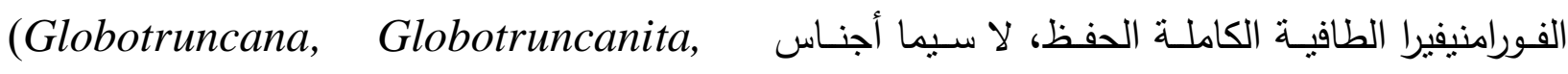
Globigerinilloides, Heterohelix) والكالسيسفيرات والفتاتات الصخرية والحياتية الدقيقة (لوحة م). وتكافئ هذه السحنة مجهرياً السحنة القياسية

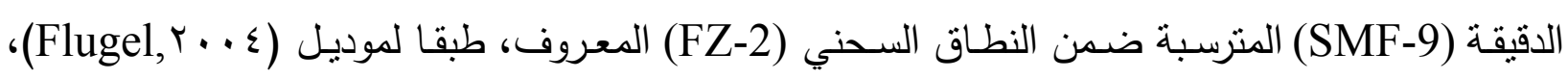

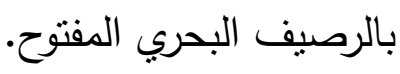

ع. سحنة الحجر الجيري المرصوص الحاوية للفورامنيفيرا الطافية الدقيقة الثانوية (P1) : (Planktonic Foraminiferal lime Packstone Submicrofacies) :

تشكل الحبيات الهيكلية النسبة المهيمنة في هذه السحنة، فهي قد تصل الى حوالي (75\%) من اجمالي

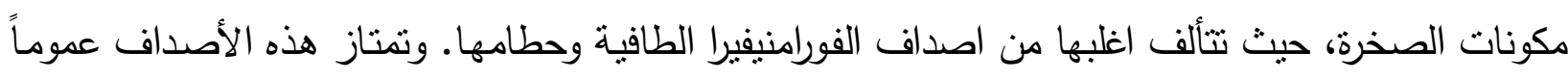

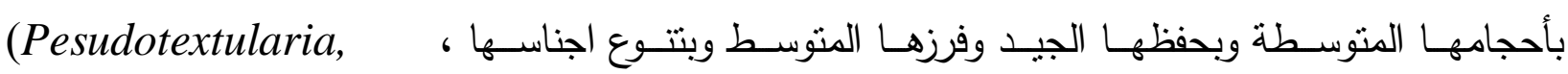
Hedbergella, Globigerinelloides, Heterohelix, Globotruncanella, Globotruncanite, 
Globotruncana) والاوستراكودا، فضـلاً عن القليل من قطع الفتاتات الحياتية. وتتغمر هذه الحبيبات جميعاً في أرضية طينية جيرية داكنة اللون (لوحة و). والسحنة عموماً تكافئ السحنة القياسية الدقيقة (SMF-2) المترسبة في النطاق السحني (FZ-2) المعروف، وطبقاً لموديل(ع ..Flugel, F)، بنطاق الرصيف البحري المفتوح. ه. سحنة الحجر الجيري المرصوص الحاوية للفتاتات العضوية الدقيقة الثانوية (P2) : (Bioclastic lime Packstone Submicrofacies) :

تتألف حوالي (75\%) من هذه السحنة مـن الحبيبات الهيكليـة، لا سيما الفتاتات والكسـارات العضـوية العائدة في معظمها الى أجناس مختلفة من الفورامنيفيرا الطافية والقاعيـة، فضـلا عن كسارات شوكيات الجلد وأحياء مختلفة أخرى. كمـا تتضـمن هذه الحبيبـات بعضـا من أصداف الفورامنيفيرا الطافية والقاعيـة الكاملـة الحفظ. وتتكل الأرضية الميكرابتية حوالي ربع المكونات الكلية لهذه السحنة (لوحة (). وهذه السحنة تكافئ السحنة القياسية الدقيقة (SMF-4) المنرسبة، وطبقاً لموديل (ع . . Flugel, (FZ)، ضمن النطاق السحني -F)

$$
\text { (3) المعروف بنطاق حافة الرصيف العميق. }
$$

6. سحنة الحجر الجيري المرصوص الحاوية للفورامنيفيرا الطافية الكروية الحجيرات الدقيقة الثانوية(P3): (Globular Chamber Planktonic Foraminiferal Packstone Submicrofacies) :

عموماً، تشكل الحبيبات الهيكلية حوالي (85\%) من المكونات الكلية لهذه السحنة، حيث تشكل الفورامنيفيرا

Rugoglobigerina, Pesudotextularia, Hedbergella, ) الطافية باجناسـها الكرويـة الحجيـرات Globigerinelloides, Heterohelix

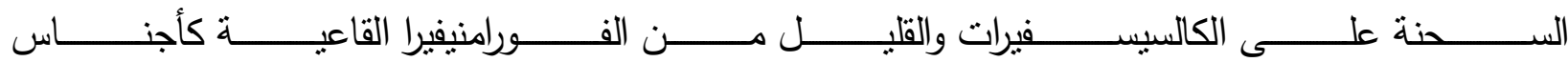
(Miliolids, Textularia, Bolivina) يظهر في هذه الســنة بعض المعـادن الموضـية النشأة كمعدني البايرايت والكلوكونايت (لوحـة ( ). وهذه

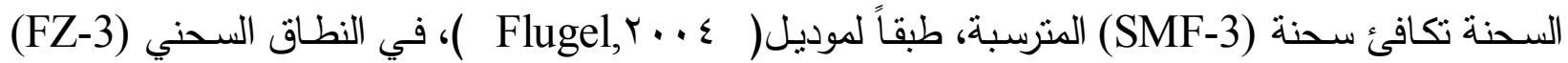
المعروف بنطاق حافة الرصيف العميق. V. سحنة الحجر الجيري المرصوص الحاملة للفورامنيفيرا الطافية الجؤجوئية الدقيقة الثانوية(P4) : (Keeled Planktonic Foraminiferal Packstone Submicrofacies) :

تشكل الحبييات في هذه السحنة حوالي (80\%) من مكونـات الصـخرة الكلية. وتتألف أغلبها من الحبييات

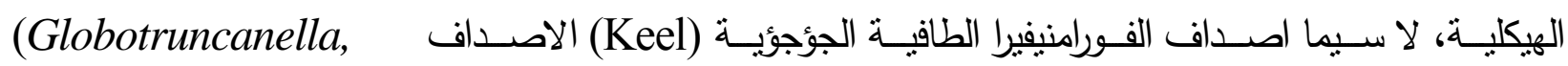

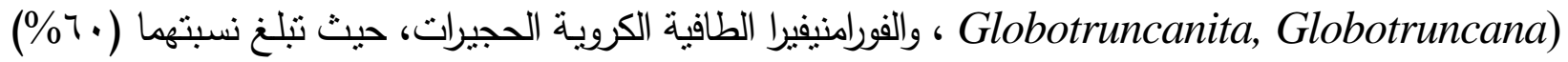
و (20\%) من مجموع الحبييات الهيكلية، على التوالي. كما يتوارد في هذه السحنة بعض الكسارات الإحيائية والقليل 


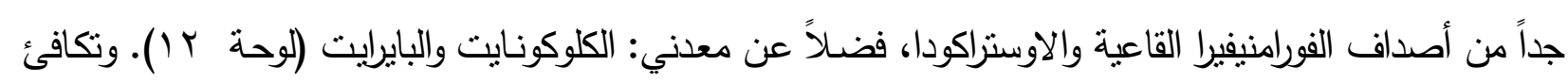
هذه السحنة، عند مقارنتها مـع السحنات القياسية، السحنة القياسية الدقيقة (SMF-10) المنترسبة، وطبقاً لموديل

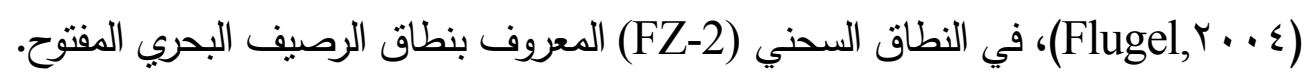

\section{مؤثرات البيئة الترسيبية}

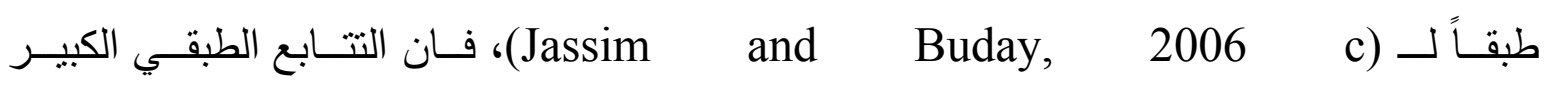
(Late Turonian - Danian Megasequence)

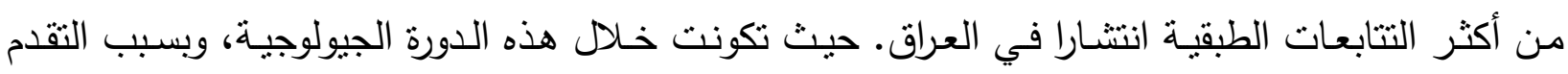
البحري الكاسح، على الرصيف المستقر أحواضـاً عريضـة ذات محاور رسوبية ممتدة باتجاه (NW-SE) Buday, (Late Campanian - Maastrichtian)

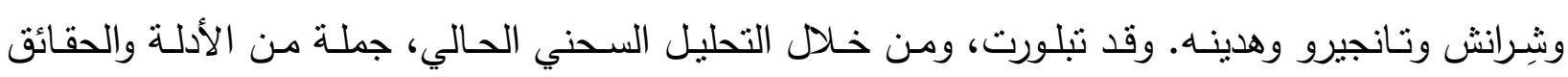
الرسوبية والحياتية المؤشرة الى طبيعة البيئة الترسيبية المرسبة لتتابعات تكوين شرانش، وفئه ولعل من ابرزها:

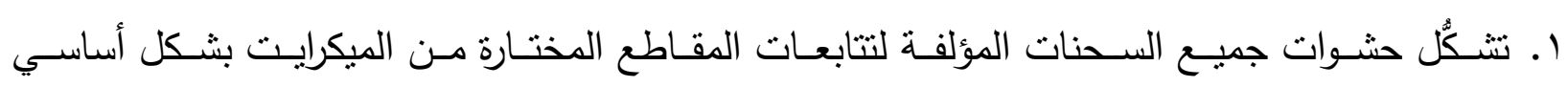
(Orthosparite) من جهة، وافتقارها الى السبار الحقبقي جهة (Mud supported) بإلى بيئة ترسيبية هادئة واقعة تحت مستوى قاعدة الأمواج المؤثرة (Flugel, 2004).

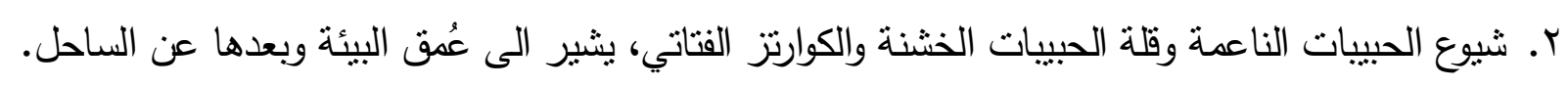

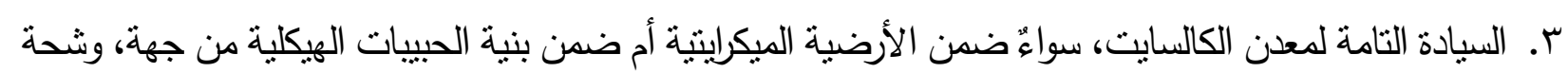

معدن الدولومايت فيهما من جهة أخرى، يؤشر الى أرجحية حصول العطليات الترسيبية في بيئة بحرية عميقة.

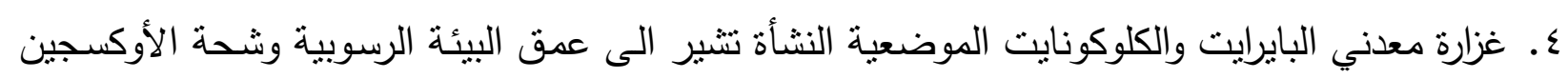
وتباطؤ العمليات الترسيبية (Nichols, 1999 ; Chilingar et al., 1967). ه. اللون القانم الذي تتصف به معظم ترسبات التكوين قد يثير الى البيئة البحرية العميقة المتسمة بشحة الأوكسجين.

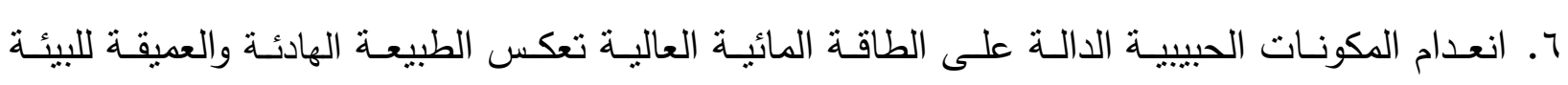
الترسيبية.

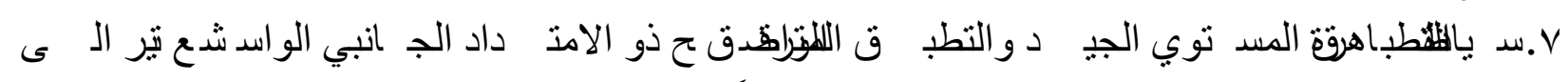
حصول الترسيب في بيئات بحرية عميقة وهادئة نسبياً.

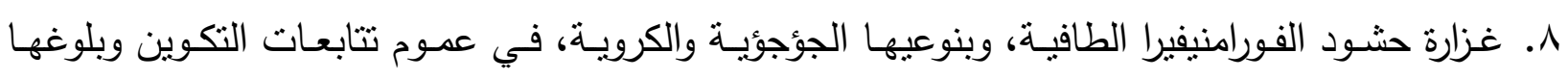

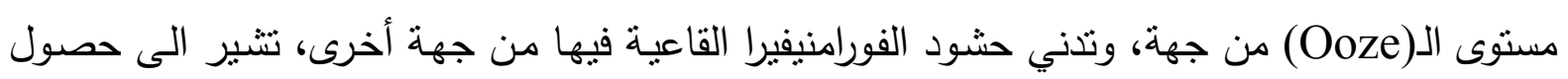
الترسيب في بيئة لجية (Pelagic) عميقة.

9 . اقتران الكالسيسفيرات مع الفورامنيفيرا الطافية في ارضية ميكرايتية يشير الى البيئة الترسيبية العميقة. 
• ا ـ ندرة الحبييات الهيكلية الدالة على البيئات العالية الطاقة تدل على بيئة رسوبية واطئة الطاقة.

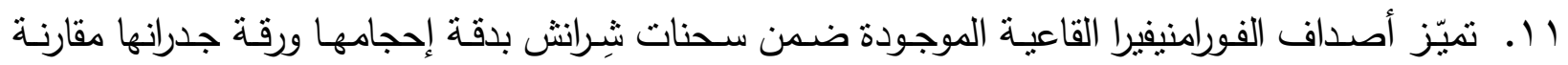
بأحجام وجدران مثيلاتها في ترسبات البيئات الضحلة أو العالية الطاقة تثبير إلى البيئة الترسيبية العميقة

\section{البيئة الرسويية}

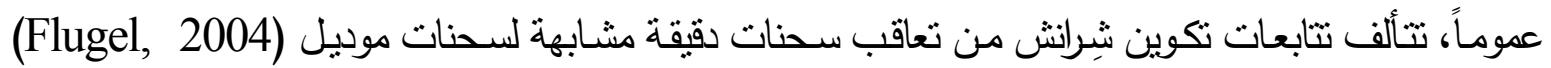
القياسية الققية الدرقمة بـ (SMF- 10, SMF- 9, SMF- 8, SMF- 4, SMF- 3, SMF- 2والمترسبة ضمن النطاقين السحنيين: نطاق (FZ-2) المعروف بالرصيف البحري المفتوح (Open Sea Shelf) ونطاق (FZ-3) المعروف بحافة الرصيف البحري العيق (Deep Sea Margin) . ومن جانب آخر، يتضح ومن خلال مقارنة

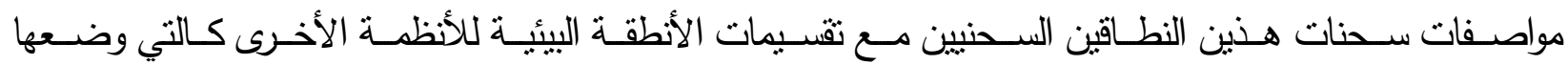

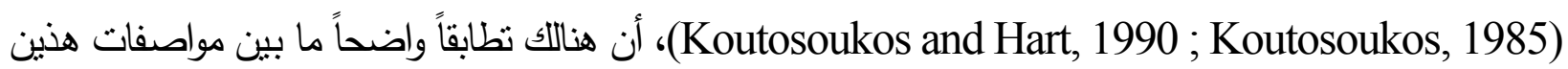

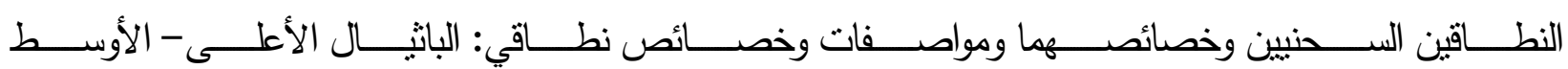

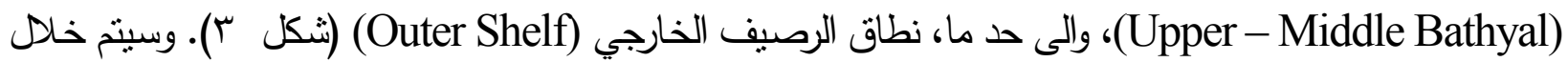

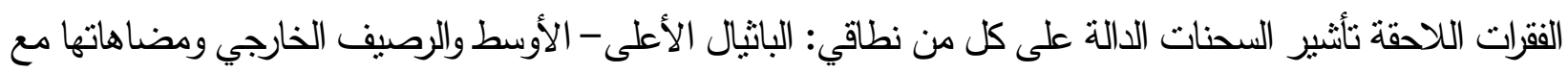
نطاقي ( Flugel, 2004 ): الثاني والثالث.

يشير التحليل السحني الحالي الى ان ترسيب تتابعات تكوين شِرانش في منطقة دهوك بدأت بترسبات انتقالية

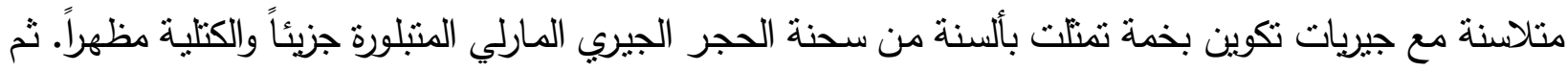
توالت بعدها سحنات تكوين شِرانش المؤلفة من تعاقب الحجر الجيري المارلي والحجر الجيري والمارل والمـارل

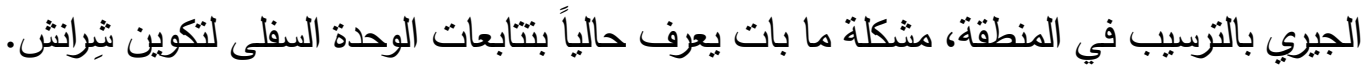


عبدالعزيز محمود الحمداني و رضوان خليل الأتروشي

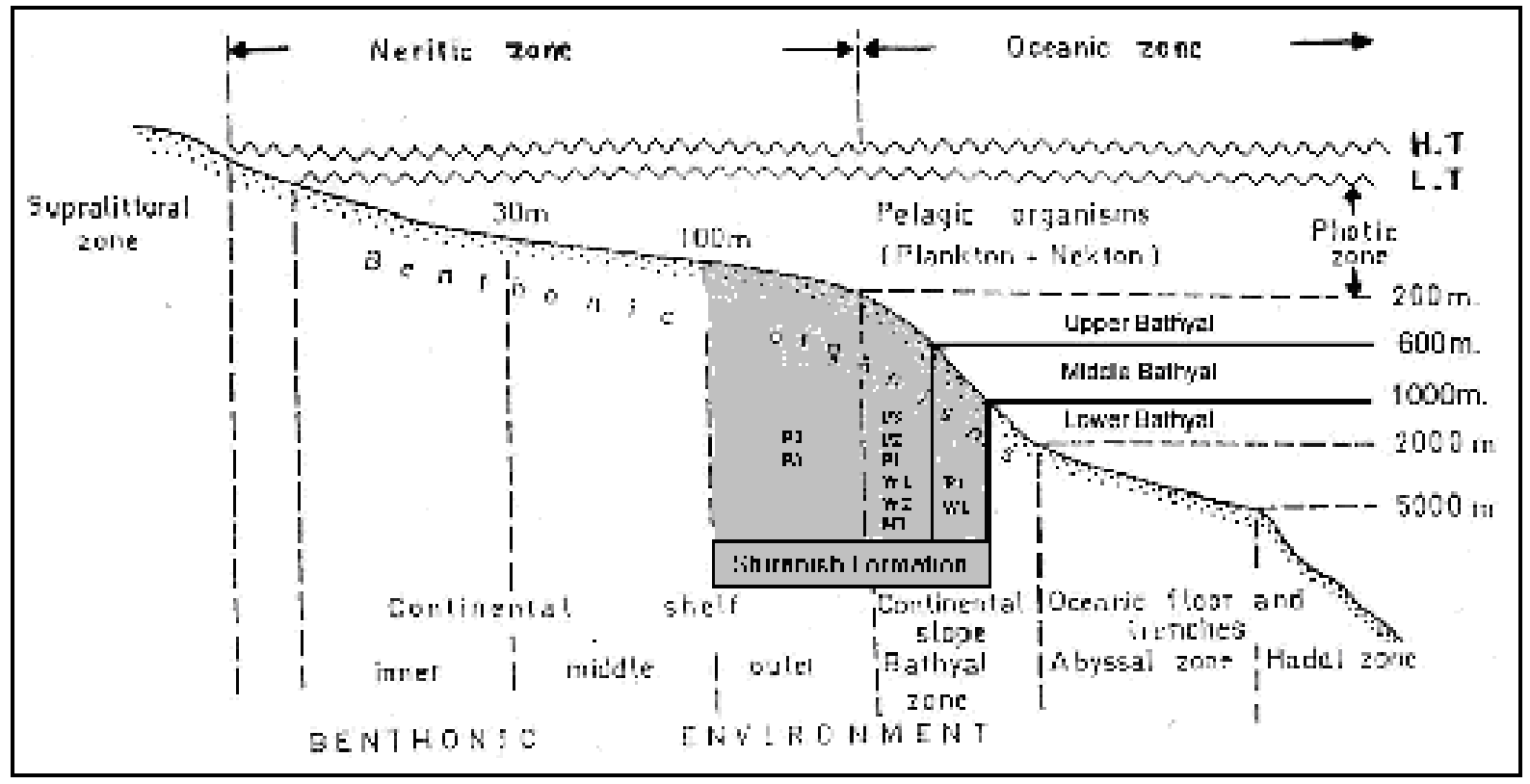

الثـكل بـ البيئـات البحربـة تبعـأ لـ (Koutosoukos, 1985)، مؤثــراً عليهـا السـحنات والأنطقة البيئية لتكوين شر انش (المنطقة المضللة).

يوضـح (الثشكل ع) طبيعـة توزيـع السحنات وسماكاتها وبيئاتها الترسبيية في المقاطع المختارة. إذ تظهر سحنة الحجر الجيري الواكي الحاوية للفورامنيفيرا الطافية (W1) في بداية تتابعات الوحدة السفلى لعموم المقاطع المختارة وبسماكات قليلة نسبياً، رغم ازديادها باتجاه الغرب، حيث مقطع زوي. ويستلل من هذه السحنة أن البيئة المرسبة لها تتمنل بنطاق الباثبال الأعلى العميقة الممتدة احياناً الى نطاق الباثبال الأوسط. بعد ذلك تدرجت هذه السحنة الى سحنة الحجر الجيري المرصوص الحاملة للفتاتات العضوية (P2) في مناطق مقطعي بري بهار وايكمالة وبسمك معتدل. ويبدو أن البيئة المرسبة لهذه السحنة كانت انتقالية وواقعة بين نطاقي: الرصبف الخارجي والباثيال الأعلى. بينما يلاحظ أن تدرج هذه السحنة (W1) في مقطع زوي كان الى سحنة الحجر الجيري الواكي الحاملة للفتاتات العضوية (W2) وظللك لافتصار بيئة هذه المنطقة على نطاق بيئة الباثبال الأعلى. خلا التتابعات الوسطى للوحدة السفلى، ترسبت في عموم المقاطع الثلاثثة وبصورة تدريجية، سحنة الحجر الجيري المرصوص الحاوية للفورامنيفيرا الطافية (P1) وبسمك كبير نسبياً. ويعتقد أن البيئة المرسبة لهذه السحنة كانت بيئة نطاق الباثيال الأعلى. ثم ترسبت بعد ذلك، وتحديداً في مقطعي: بري بهار وزوي وبسمك قليل، سحنة الحجر الجيري الطيني الحاوية للفورامنيفيرا الطافية (M1) وذلك تحت وطأة بيئة نطاق الباثيال الأعلى، في حين لم تظهر هذه السحنة (M1) في تتابعات مقطع ايكمالة. ثم سادت بعد ذللك، وبصورة تدريجية في مقطع ايكمالة وبصـورة حـادة في المقطعين الآخـربن، ســنة الحجر الجيـري المرصـوص الحاويـة للفـورامنيفيرا الطافيـة ذات الحجيرات الكروية (P3). ويعتقد أن البيئة المرسبة لهذه السحنة كانت بيئة نطاق الباثيال الأعلى الممتدة احياناً إلى بيئة نطاق الرصيف الخارجي. ثم استمر عطاء نطاق الباثيال الأعلى في منطقة ايكمالة تحديداً، فرسبت ســـة الحجر الجيـري الطيني الحاويـة للفورامنيفيرا الطافيـة (M1). واختتمـت تتابعـات الوحدة السـلى للتكوين 
وبصورة تدريجية بترسبات تضحلية نسبياً تمنتل بسحنة الحجر الجيري المرصوص الحاوبية للفورامنيفيرا الطافية (P1)، رغم مرورها المتدرج في مقطع زوي بسحنة الحجر الجيري الواكي الحاويـة للفورامنيفيرا الطافية (W1)، وذلك لإستمرار هيمنة نطاق الباثيال الأعلى واحياناً نطاق الباثيال الأوسط العميقة نسبياً.

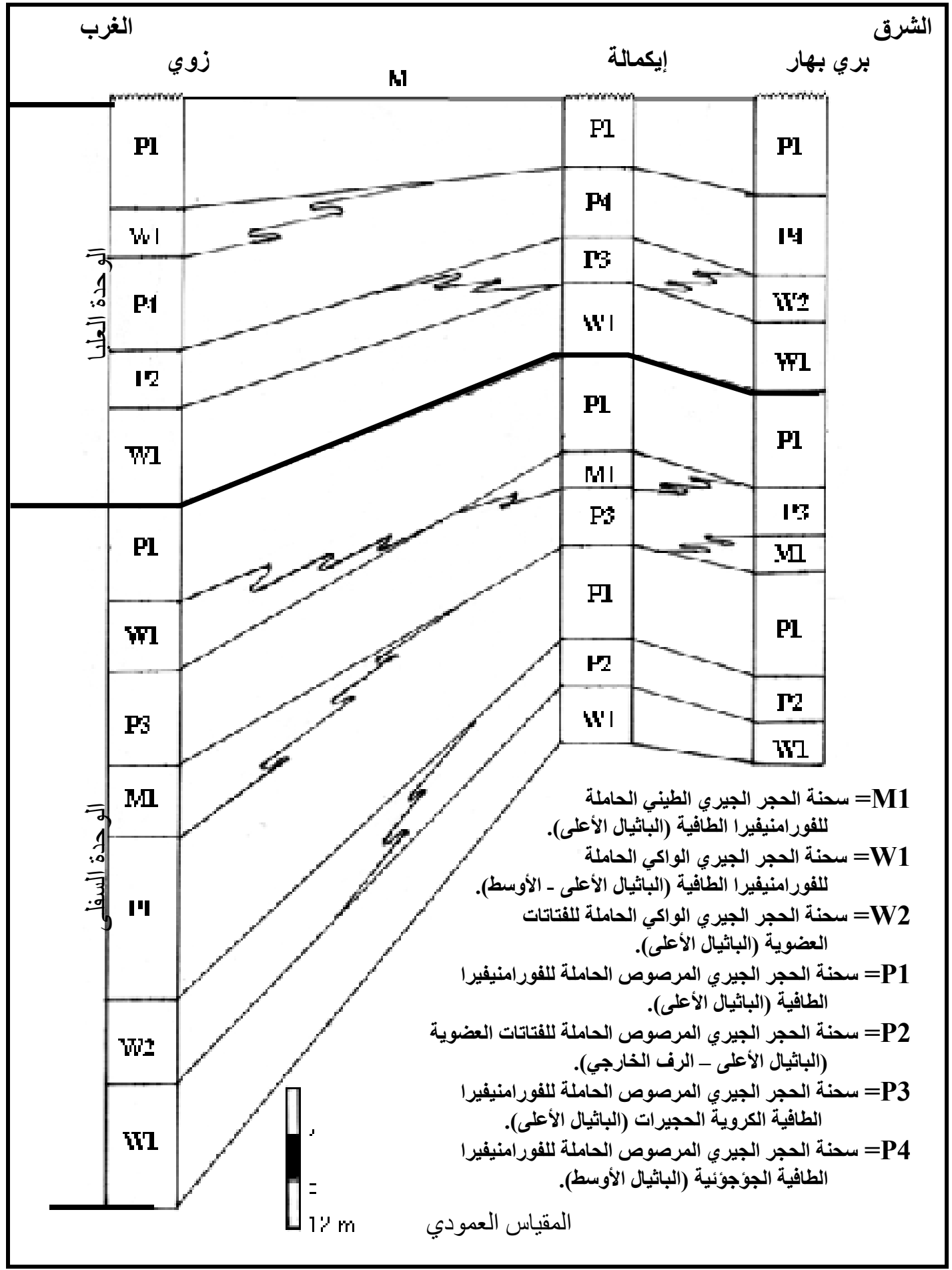

الثكل : التغيرات السحنية الجانبية والعمودية في منطقة الدراسة وأنطقتها المرسبة.

أُّتهلت تتابعات الوحدة العليا للتكوين في عموم المقاطع الثلاثة، وبتطور تدريجي واضـح نحو الأجزاء الغربيـة لمنطقة الدراسـة (مقطع زوي)، بسحنة الحجر الجيري الواكي الحاويـة للفورامنيفيرا الطافيـة (W1)، 


\section{عبدالعزيز محمود الحمداني و رضوان خليل الأتروشي}

مشيرة بذلك الى هيمنة بيئة نطاق الباثيال الأعلى - الأوسط في عموم المنطقة. وبعد إتمام عمليات توضع هذه السحنة، يبدو أن الظروف البيئية قد تباينت فيما بين المقاطع الثتاثة، إذ ترسبت وبصورة تدريجية، سحنة الحجر الجيري الواكي الحاوية للفتاتات العضوية (W2) في مقطع بري بهار عاكسة بذلك تواصل بيئة نطاق الباثيال الأعلى فيها، في حين ترسبت، وبصورة حادة، سحنة الحجر الجيري المرصوص الحاوية للفورامنيفيرا الطافية ذات الحجيرات الكروية (P3) في مقطع ايكمالة وسحنة الحجر الجيري المرصوص الحاوية للفتاتات العضوية (P2) في مقطع زوي، مشيرةً بذلك الى بيئة نطاق الرصيف الخارجي الممتدة إلى نطاق الباثيال

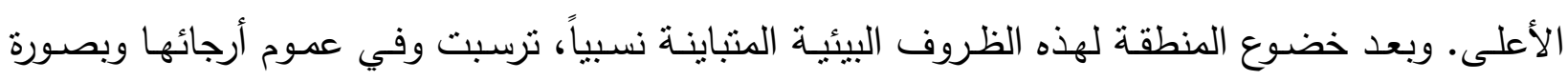
فجائية، سحنة الحجر الجيري المرصوص الحاوية للفورامنيفيرا الطافية ذات الأشكال الجؤجؤية (P4) مشيرةً بذلك الى أقصى عمق ترسيبي وصلت إليه بيئة ترسيب تكوين شِرانش في المنطقة، والتي تمثلت ببيئة نطاق الباثيال الأوسط. واكتملت نتابعات الوحدة العليا بترسيب سحنة نسبياً تضحلية مؤلفة من الحجر الجيري المرصوص الحاوية للفورامنيفيرا الطافية (P1) مخنتمة بذلك ثتابعات التكوين في عموم المنطقة، رغم مرورها بسـنة إنتقاليـة في الأجزاء الغربيـة من منطقة الدراسـة (مقطع زوي) تمنلت بسحنة الحجر الجيري الواكي الحاوية للفورامنيفيرا الطافية (W1) المتوسطة العمق. وهكذا تشير كافة الدلائل المستوحاة من هذه الدراسـة السـحنية إلىى أن مجمل تتابعـات تكوين شِـرانش قد ترسبت في أنطقـة بيئية بحربـة حوضية عميقة لجيـة دنها (Pelagic) نطـاقي الباثبال الأعلى -الأوسط، الممتد أحيانـاً إلى نطاق الرصيف الخـارجي، وعلى النحو الموضـح في

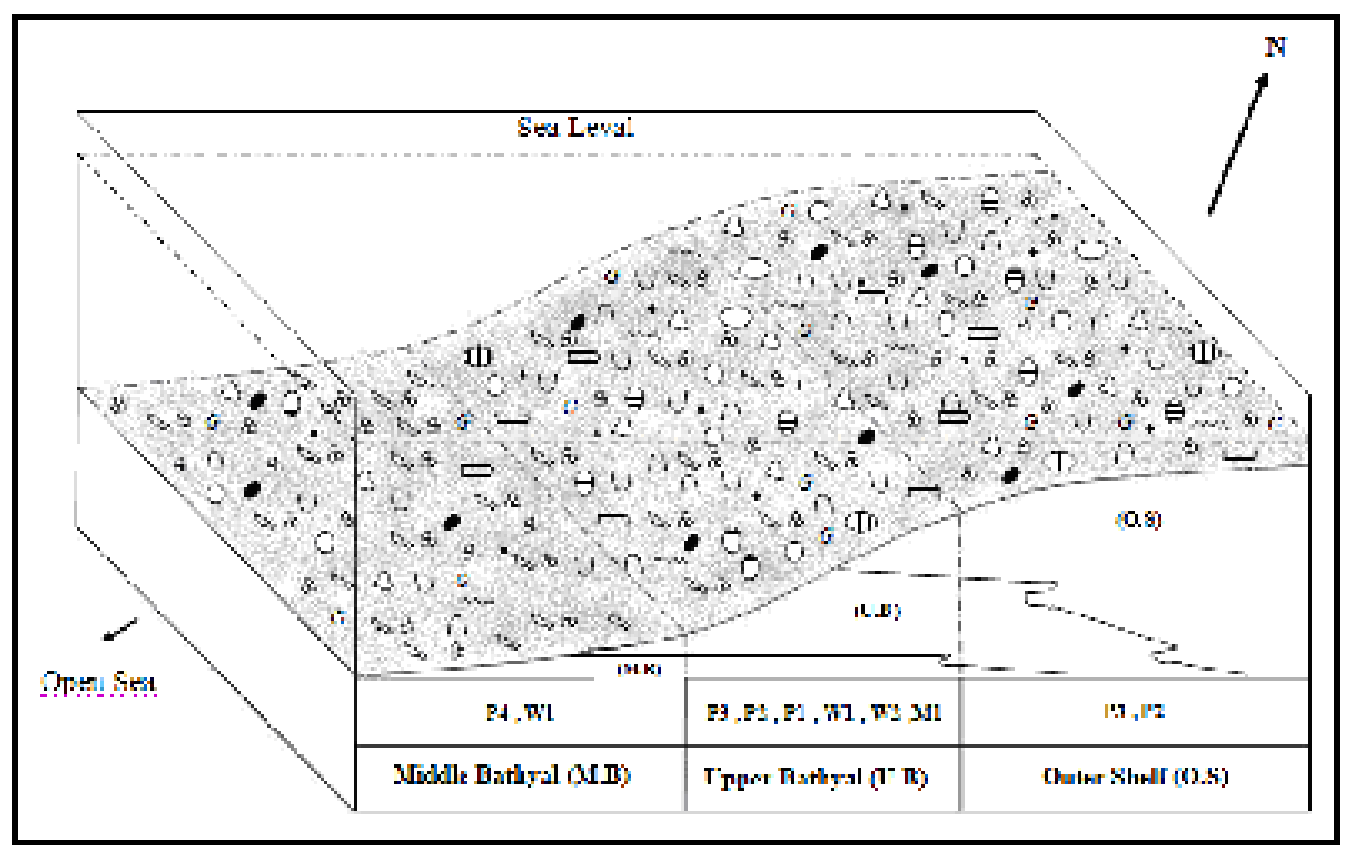




\section{المناقثة والاستنتاجات}

تعكس نتائج التحليل السحني والبيئي لإجمالي تتابعات تكوين شبرانش في منطقة دهوك تعمقاً بحرياً

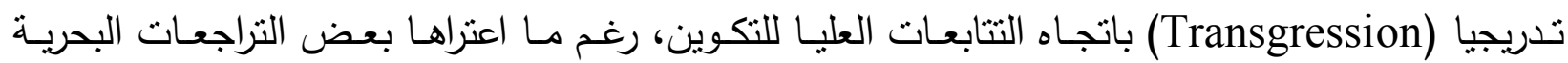

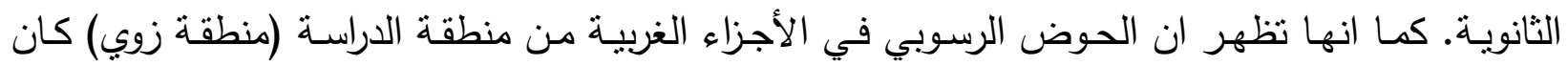

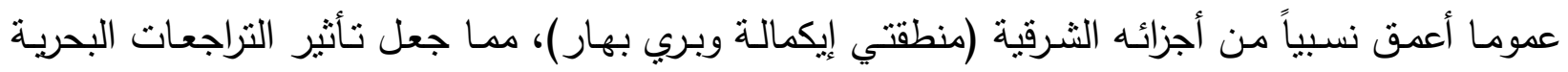

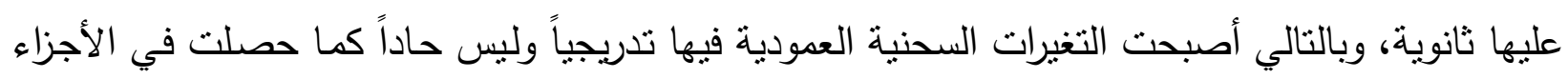

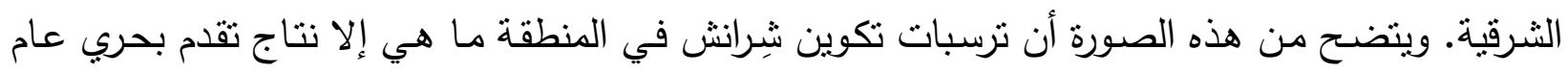

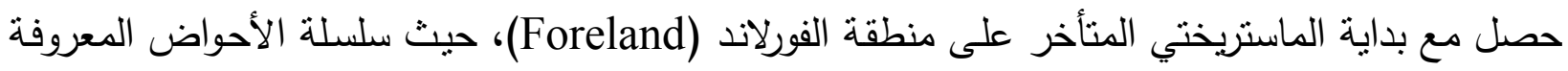

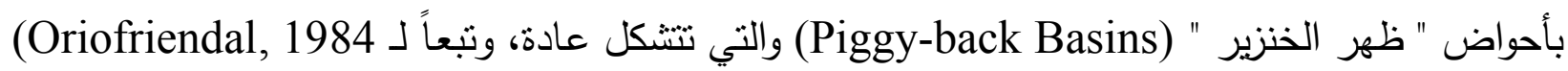
(in Nichols, 1999) يُعتقد أن الحافة الخاملة للصفيح العربي، والتي أمست فيما بعد تُعرف بالفورلاند كانت مجزأة الى عدة

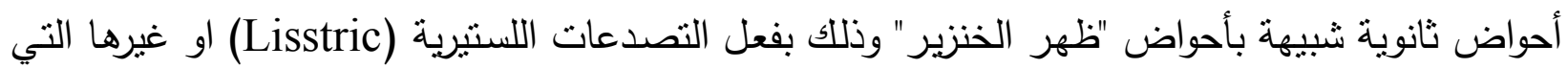

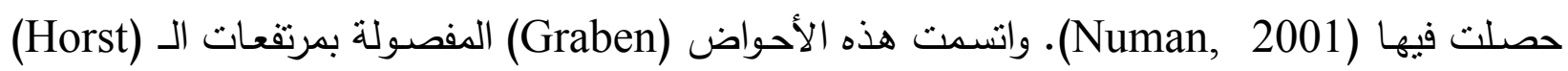

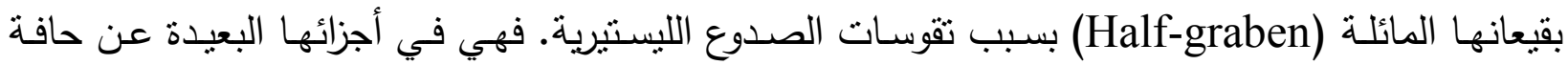

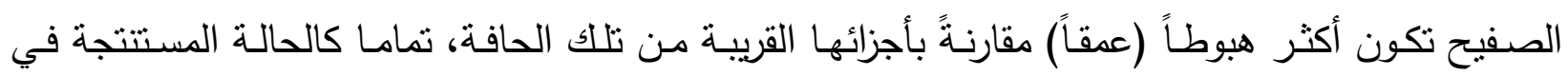

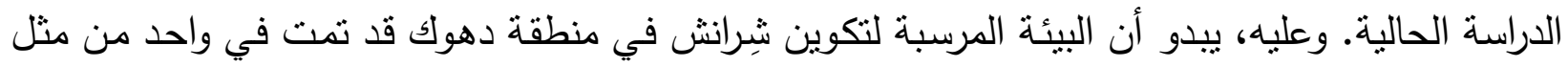

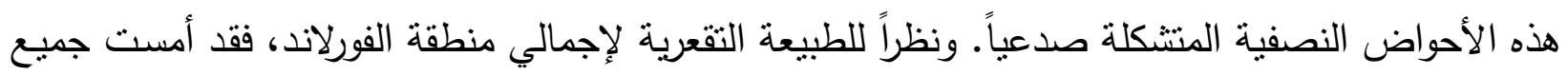

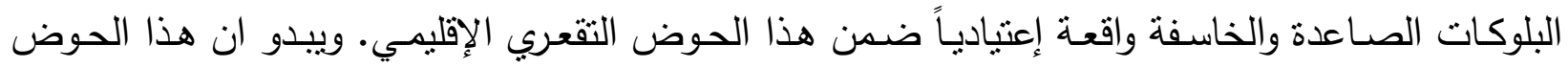

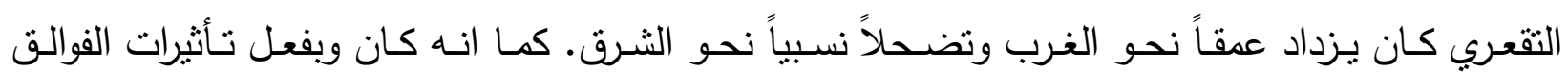

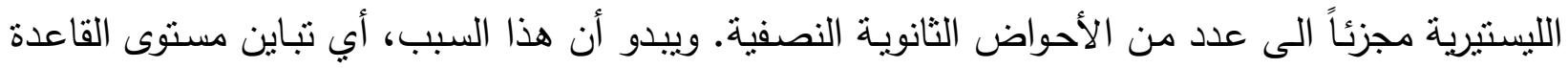

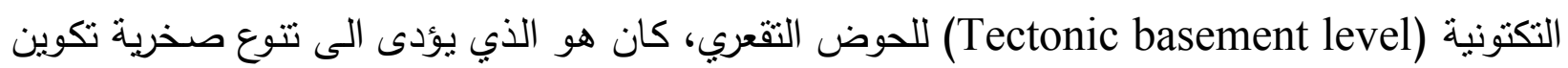
شرانش وتباين سمكه من منطقة إلى أخرى. 


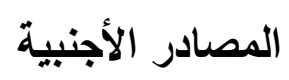

Al-Atroshi, R. K. H. Y .. V. Sedimentology of Shiranish Formation at Dohuk Area, Unpublished M.Sc. Thesis, Coll. of Science, Mosul University, Iraq, Ir) p. (in Arabic).

Al-Qayim, B., Habib, H. R. and Al-Dyni, N. 1986. Petrology and Geochemistry of Shiranish Formation (Type Section) towards Sedimentary Facies interpretation, Jour. Geol. Soci. Iraq, Vol. 19, No. 3, pp. 123 - 136.

Bellen, Van. R. C., Dunnington, H .V., Wetzel, R. and Morton ,D. m. 1959. Lexique Stratigraphique International Asie, Fascicule, 10a, Iraq, Centeral National deal Recherches Scientifique, Paris, 333 p.

Buday, T. 1980, The Regional Geology of Iraq : Stratigraphy and Paleogeography, Dar Al-Kutub publishing, House, University of Mosul, Mosul, Iraq, $445 \mathrm{p}$.

Chilingar, G. V., Bissell, H. J. and Wolf, K. H. 1967. The Diagenesis of Carbonate Rocks. In : Larsen, G. and Chilingar, G.V. (Eds.), in Diagenesis In Sediments, Amsterdam, pp. 179 - 322.

Dunham, R. J. 1962. Classification of Carbonate Rocks According to Depositional Texture, in : Ham, W.E. (ed), Classification of Carbonate Rocks, A. A. P. G. Mem.-1, Tulsa, Okla., pp. 108 - 121.

Dunnington, H. V. 1958. Generation, Migration, Accumulation and Dissipation of Oil in Northern Iraq, A.A.P.G. In: Geoarbian (2005), Vol. 10, No. 2, pp. 39 - 84.

FAO 1994. Internal Unpublished FAO Report.

Flugel, E. 2004. Microfacies of Carbonates Rocks, $2^{\text {nd }}$ ed., Springer, Berlin, 976 p. Jassim, S. Z. and Buday, T. 2006 a. Tectonic Framework, In : Jassim, S. Z. and Goff, J. C. (eds.), Geology of Iraq, Published by Dolin, Prague and Moravian Museum, Brno, pp. 45 - 55.

Jassim, S. Z. and Buday, T. 2006 b. Units of the Unstable Shelf and the Zagros Suture, In: Jassim, S. Z, and Goff, J. C. Geology of Iraq, Published by Dolin Prague and Moravian Museum, Brno, pp. 71 - 83.

Jassim, S. Z. and Buday, T. 2006 c. Late Turonian - Danian Megasequence Ap9, In : Jassim, S. Z. and Goff, J. C., Geology of Iraq, Published by Doline, Prague and Moravian Museum, Brno, pp. 141- 154.

Kassab, I. I. 1973. Planktonic Foraminiferal of the Shiranish Formation Type locality (Northern Iraq), Jour. Geol. Soci. Iraq, Vol. 6, pp. 100 - 109. 
التحليل السحني وبيئة ترسيب تكوين شِرانش في طية بيخير ، منطقة دهوك، شمال العراق

Kassab, I. I. 1978. Biostratigraphy of Upper Cretaceous-Lower Tertiary of North Iraq, Annales Des Min. Geol., Tunis, Vol. 28, No. 2, pp. 277 - 325.

Koutsoukos, A. M. 1985. Distribuicae Paleobatimetrica de Foraminiferos Benthonic osdo Cenozoic, Margem Continentalatlantica. Brazil, Combase. Congresso Brasileiro de Geol., Vol. 2, pp. 685 - 696.

Koutosoukos, A. M. and Hart, M. B. 1990 Cretaceous Foraminiferal Morphogroub Distribution Patterns Palaeocommunities and Trophic Structures : A case Study from the Sergipe Basin, Brazil, Transections of the Royal Society of Edinburgh, Earth Sciences, No. 81, pp. 221- 246.

Munium, A. 1976. Upper cretaceous and Lower Tertiary Foraminifera of North Iraq, Dohuk area, S. O. M., Unpublished Report, Baghdad, 57p.

Nichols, G. 1999. Sedimentology and Stratigraphy,Blackwell Publishig Co., 355 p. Numan, N. M. S. (2001) : Cretaceous and Tertiary Albian Subduction History in northern Iraq, Iraqi Jour. of Earth Soc. Vol. 1, pp. 59-74.

Tyson, R. V. and Pearson, T. H., 1991. Modern and ancient continental shelf anoxia: An overview, Geological Society, London, Special Publications, Vol. 58, pp. 1-24. 


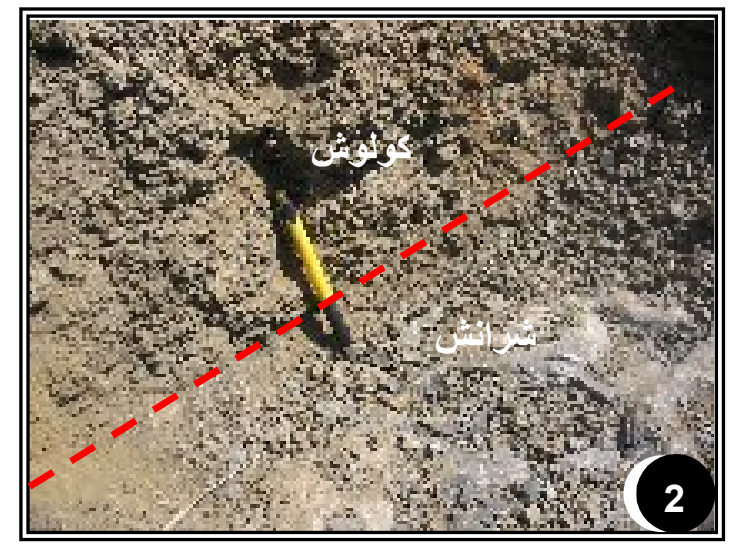

سطح التماس العلوي لتكوين شي انش غي ر روبر

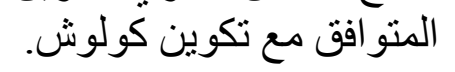

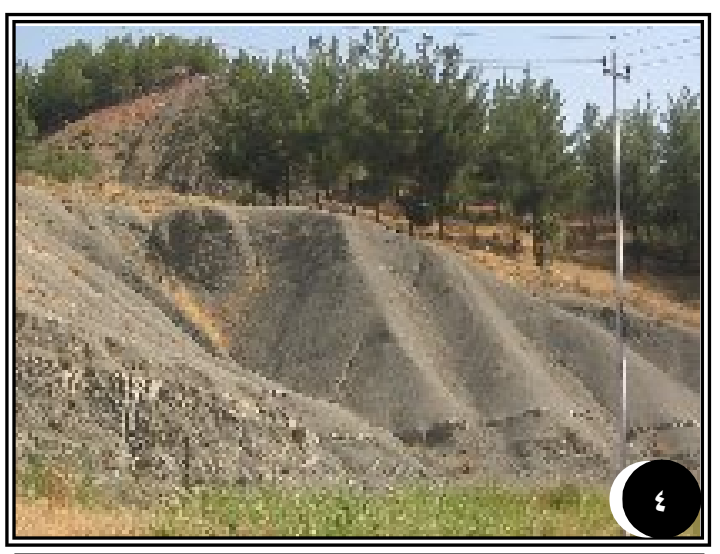

تعاقبات الوحدة العليا ، وهي نحيفة التطبق

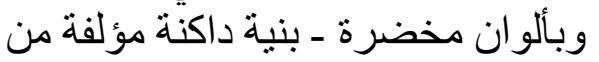

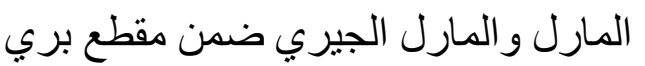
بهار.

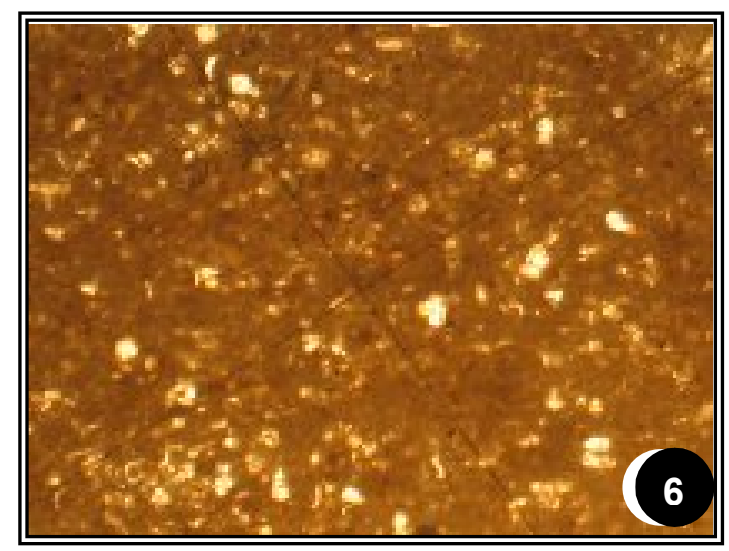

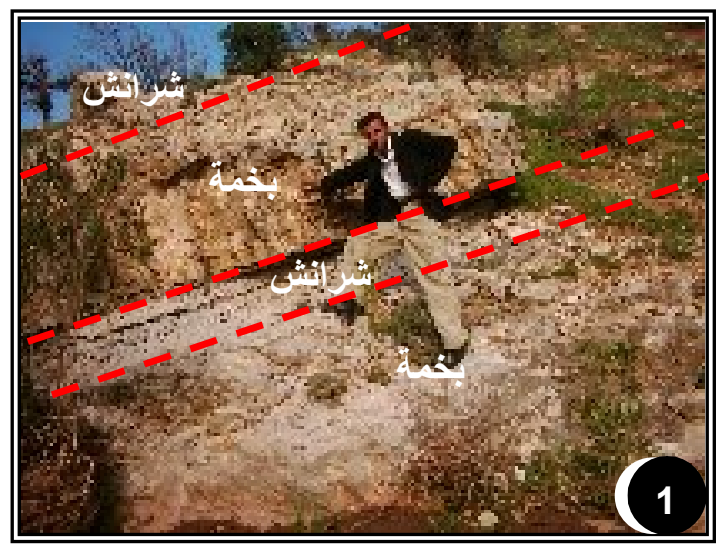

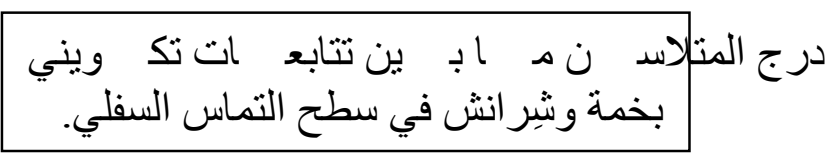

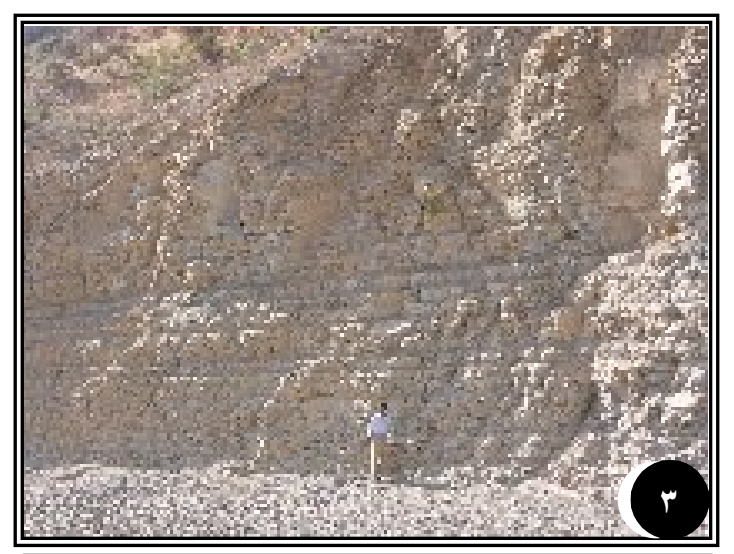

$$
\begin{aligned}
& \text { تنتابعات الوحدة السفلى ، وهي جيدة التطبق }
\end{aligned}
$$

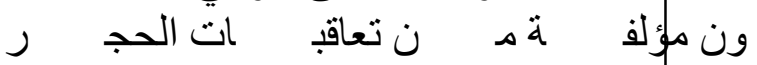

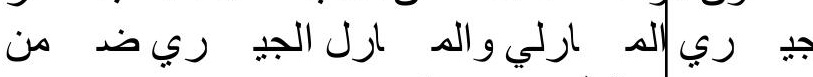

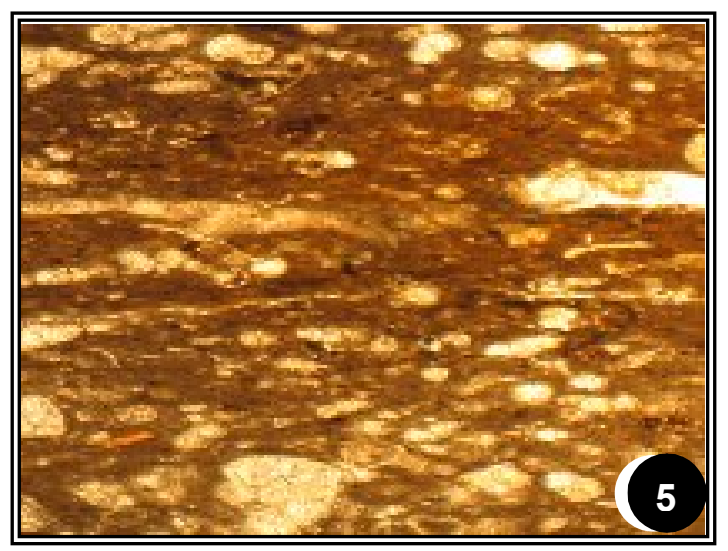


التحليل السحني وبيئة ترسيب تكوين شِرانش في طية بيخير ، منطقة دهوك، شمال العراق

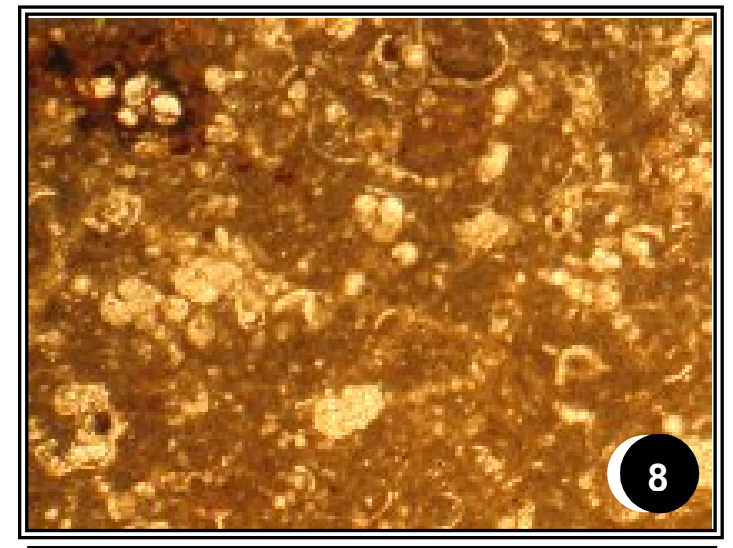

لإلي الجي

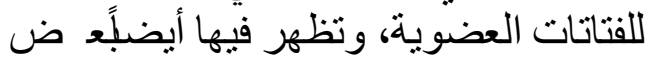
أصداف الفور امنيفير ا الطافية (X5).

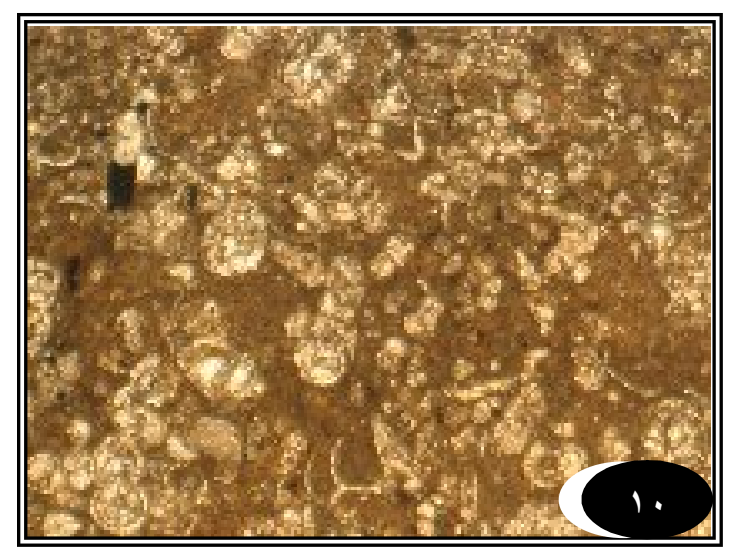

سحنة الحجر الجيري المرصد وص الحاما

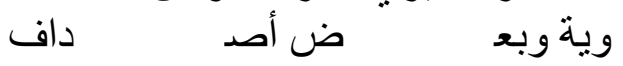

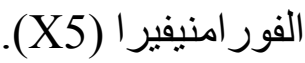

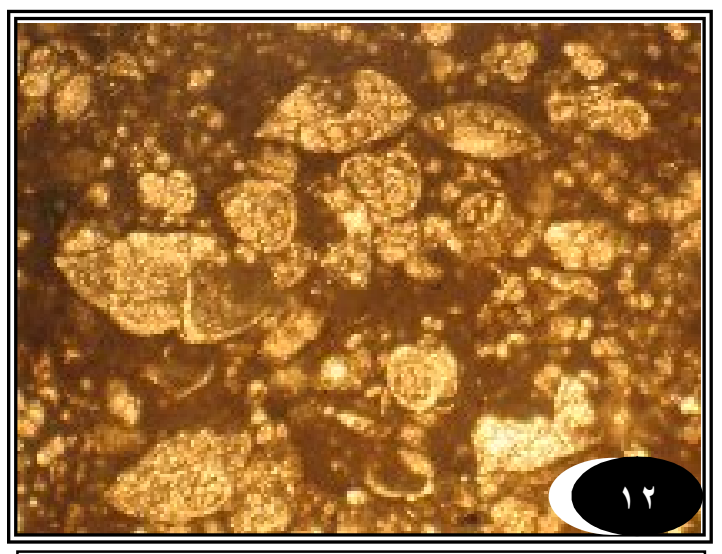

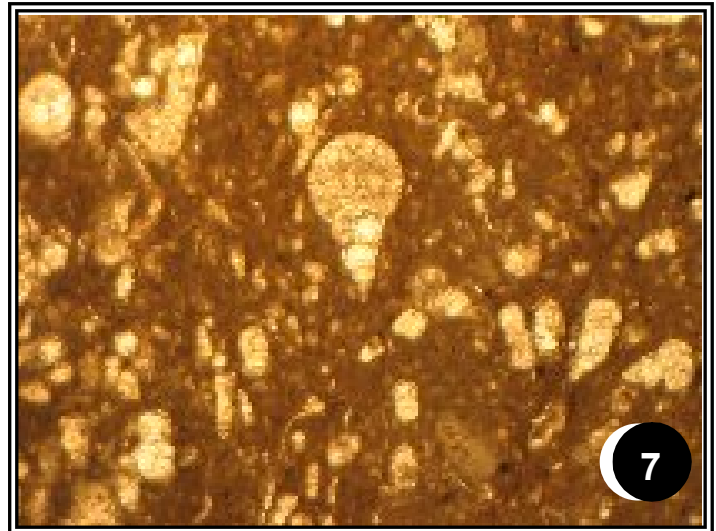

سد

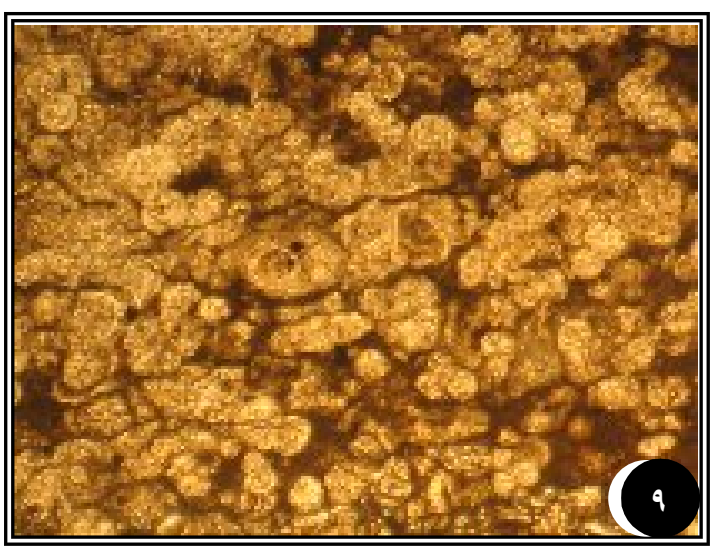

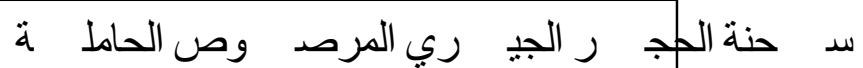

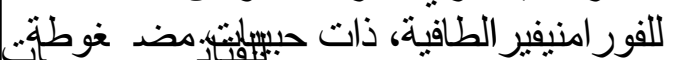

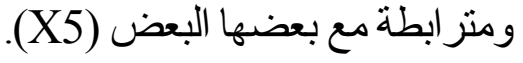

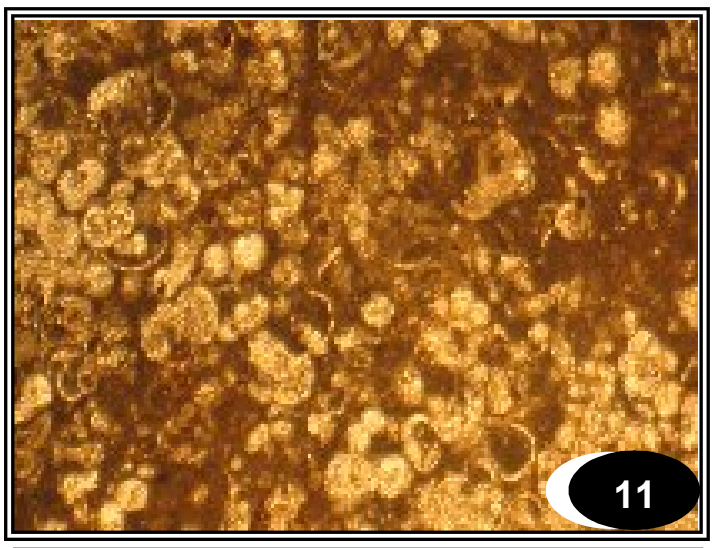


عبدالعزيز محمود الحمداني رضوان خليل الأتروشي 